\title{
Morphological and genetic characterization of marine filamentous cyanobacterium Geitlerinema isolated from Thailand
}

\author{
Nichanan Tinpranee $^{\mathrm{a}}$, Worakrit Worananthakij ${ }^{\mathrm{a}, \mathrm{b}}$, Aran Incharoensakdi ${ }^{\mathrm{c}}$, Saranya Phunpruch ${ }^{\mathrm{a}, \mathrm{b}, *}$ \\ a Department of Biology, Faculty of Science, King Mongkut's Institute of Technology Ladkrabang, \\ Chalongkrung Road, Bangkok 10520 Thailand \\ b Bioenergy Research Unit, Faculty of Science, King Mongkut's Institute of Technology Ladkrabang, \\ Chalongkrung Road, Bangkok 10520 Thailand \\ c Laboratory of Cyanobacterial Biotechnology, Department of Biochemistry, Faculty of Science, \\ Chulalongkorn University, Phyathai Road, Bangkok 10330 Thailand
}

*Corresponding author, e-mail: saranya.ph@kmitl.ac.th

Received 27 Jun 2017

Accepted 27 Mar 2018

\begin{abstract}
Geitlerinema is a dominant benthic filamentous cyanobacterium found in the Gulf of Thailand and the Andaman Sea. We investigate the diversity of Geitlerinema strains isolated from Thailand using morphological and molecular characterization. No morphological differences were observed in the Geitlerinema isolates. Nucleotide sequencing and phylogenetic analyses of the 16S rDNA, the 16S-23S rRNA internal transcribed spacer (16S-23S ITS) and the $c p c B-c p c A$ intergenic spacer ( $c p c B-c p c A$ IGS) showed that the marine Geitlerinema isolates belong to a single cluster that includes marine Geitlerinema sp. Flo1 and Geitlerinema sp. PCC7105 but is distinct from a type species, Geitlerinema splendidum and Geitlerinema strains which were recently transferred to the genus Anagnostidinema. From our results, it is confirmed that marine Geitlerinema differs from true freshwater Geitlerinema and is proposed to be a new genus in Oscillatoriales. In addition, using random amplification of polymorphic DNA (RAPD), the marine Geitlerinema isolates in this study could be classified into eight clades; however, this classification revealed no correlation with the geographic locations.
\end{abstract}

KEYWORDS: marine Geitlerinema, morphology, genetic diversity, 16S rDNA, 16S-23S ITS, cpcB-cpcA IGS, RAPD

\section{INTRODUCTION}

Cyanobacteria are prokaryotes capable of oxygenic photosynthesis. They can be generally found in terrestrial, freshwater, brackish and marine ecosystems. Some cyanobacteria can also inhabit extreme environments such as hot springs, frozen lakes in Antarctica, hypersaline environments or hot deserts. Cyanobacteria can be taxonomically classified by genus based on colony or trichome morphology, ultrastructure character, cell physiology and biochemistry, culture conditions, habitat or ecology, and genetic characteristics ${ }^{1}$.

Geitlerinema is a filamentous cyanobacterium belonging to the order Oscillatoriales ${ }^{1}$. Geitlerinema was originally classified in the LPP-B 'Oscillatorian' group ${ }^{2}$ but was later simultaneously assigned to a subgenus of the genus Phormidium ${ }^{3}$ and designated as "Oscillothrix"4. Geitlerinema was later re-classified as a new genus of oscillatorialean cyanophytes in the family Pseudanabaenaceae $^{5}$. Geitlerinema can be found in different aquatic habitats such as freshwater or marine environments ${ }^{2,6,7}$. The morphology of Geitlerinema is a thin, highly motile, flexuous gliding trichome with rounded shape at both ends and the obligate absence of a sheath. Additional morphological characteristics such as cellular dimension and width, the number and localization of granules, and other ultrastructural characteristics have been well-studied in some strains of Geitlerinema ${ }^{8-10}$; however, morphological data are not sufficient for species-level identification.

Many molecular techniques have been used to investigate the genetic diversity and phylogenetic relationships among cyanobacteria. Variable nucleotide sequence regions such as the 16S-23S rRNA internal transcribed spacer region (16S-23S 
ITS) and the intergenic spacer region of the phycocyanin locus ( $c p c B-c p c A$ IGS) have been targeted for phylogenetic analysis in cyanobacteria ${ }^{11-15}$. In addition, random amplification of polymorphic DNA (RAPD) has been used to examine the correlation of morphology, genetics, and geography among strains of the marine cyanobacterium Leptolyngbya valderiana (Pseudanabaenaceae) ${ }^{16}$. Molecular techniques, including 16S rDNA restriction analysis and nucleotide sequencing of $16 \mathrm{~S}$ rDNA and the phycocyanin intergenic spacer, were employed to investigate genetic variation among Geitlerinema at the species or population levels $6,10,17$. Using both morphological and 16S rDNA molecular analysis, Geitlerinema has been verified as a polyphyletic microorganism $^{18-20}$.

Only few studies on cyanobacterial diversity in Thailand have been reported ${ }^{21-23}$. There have been studies on a diversity of cyanobacteria from soil ecosystems and agricultural areas in North, Central and Northeast part of Thailand ${ }^{21}$, from hot springs in Thailand ${ }^{22}$ and from a man-made solar saltern in Petchaburi province, Thailand ${ }^{23}$. Until now, the diversity of marine cyanobacteria isolated from Thailand has not yet been reported. Thailand is a Southeast Asian country harbouring two coasts, the Gulf of Thailand, connected to the Pacific Ocean, and the Andaman Sea, connected to the Indian Ocean. In this study, most of marine cyanobacteria isolated along the coastline of Thailand were found to belong in genus Geitlerinema. This study aimed to investigate morphological and phylogenetic diversity among Geitlerinema populations in two different coastlines of Thailand. It is possible that marine Geitlerinema isolates in this study might be morphologically or genetically diverse from each other and in addition, they might be distinct from the previously reported freshwater Geitlerinema strains. Hence morphology and molecular characterizations using 16S rDNA, 16S-23S ITS and cpcB-cpcA IGS nucleotide sequencing and RAPD pattern analysis of Geitlerinema isolates were investigated.

\section{MATERIALS AND METHODS}

\section{Collection and isolation of cyanobacteria}

Cyanobacterial strains in this study were isolated from samples of seawater, stones, sand, and shells collected from the Gulf of Thailand and the Andaman Sea of Thailand (Fig. 1). The samples were collected from 40 coastal locations of 6 provinces in Thailand during June to December in 2013. The approximately 20-40 samples from each location

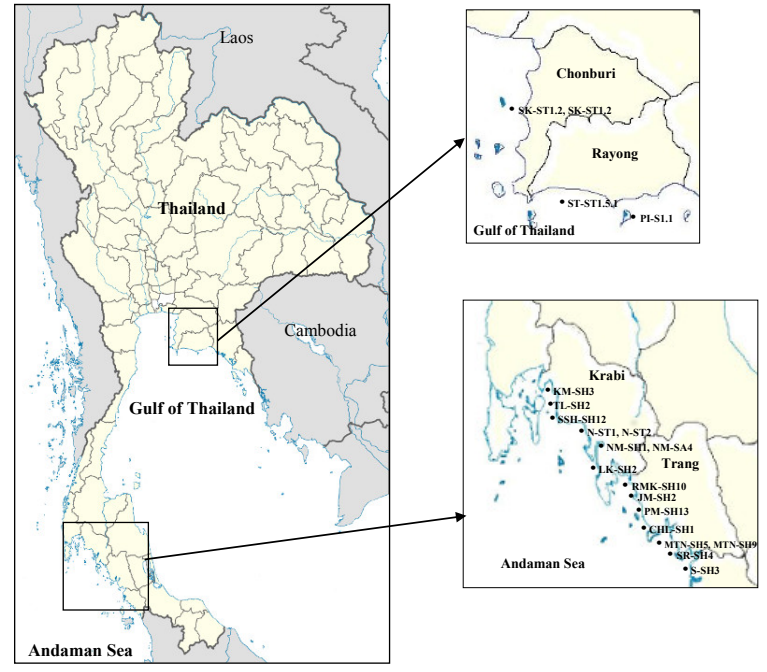

Fig. 1 Map of sampling collection locations.

were randomly collected. Planktonic cyanobacterial strains were isolated from seawater whereas benthic cyanobacterial strains were isolated from stones, sand, and shells. All samples from each environment were inoculated in flasks containing liquid ASN III medium ${ }^{2}$. The flasks were then incubated at $30^{\circ} \mathrm{C}$ under light illumination of $30 \mu \mathrm{mol}$ photons $\mathrm{m}^{-2} \mathrm{~s}^{-1}$ for 7-30 days or until green colour in medium appeared. In case of planktonic cyanobacterial isolation, seawater samples at $10-30 \mathrm{~cm}$ depth were filtered onto $20 \mu \mathrm{m}$ mesh plankton net and the biomass on the filter was subsequently inoculated in medium and cultivated under corresponding conditions. Each filament or colony of cyanobacteria from stones, sand, shells, and water were isolated by a single cell isolation technique under a stereomicroscope (Nikon SMZ745T, Japan) ${ }^{24}$. The cyanobacterial cells were washed several times with autoclaved ASN III medium and transferred onto new solid ASN III agar plates. The monoclonal cyanobacterial culture was used in all experiments.

\section{Cyanobacterial cultivation}

Cyanobacterial isolates were cultivated in 250-ml Erlenmeyer flasks containing $100 \mathrm{ml}$ of liquid ASN III medium. Cells were grown at $30^{\circ} \mathrm{C}$ with shaking at $120 \mathrm{rpm}$ under white-light illumination of $30 \mu \mathrm{mol}$ photons $\mathrm{m}^{-2} \mathrm{~s}^{-1}$ for 14 days.

\section{Morphological analysis}

The trichome shape, cellular width and length, cell wall constrictions, shape of apical cells, the presence or absence of calyptrae, and the number of 
cyanophycin granules were determined in Geitlerinema isolates under a light microscope (Olympus CX31, Japan). In each Geitlerinema isolate, dimension of ten vegetative cells per trichome was measured in twenty trichome cells by calculation magnification of images using the reference scale bar. Trichome cells were photographed under magnification with video camera system (Nikon Bx51, Japan) using NIS-Elements Ver. 3.2 software (Nikon, Japan).

\section{Genomic DNA isolation}

One loop (approximately $40 \mathrm{mg}$ wet weight) of purified Geitlerinema cells grown on ASN III agar was suspended in $400 \mu \mathrm{l}$ of TE buffer (10 mM Tris$\mathrm{HCl}$ and $1 \mathrm{mM}$ EDTA, $\mathrm{pH}$ 8.0) in a microcentrifuge tube. Genomic DNA was isolated according to the protocol of Golden et $\mathrm{al}^{25}$.

\section{PCR amplification and DNA sequencing}

DNA fragments of 16S rDNA, 16S-23S ITS, and $c p c B-c p c A$ IGS of twenty marine Geitlerinema isolates were amplified by PCR using primer pairs F16SrDNACyano (5'-GCTCAGGATGAACGCTGGC G-3') and R16SrDNACyano (5'-CGGCTACCTTGTTA CGACTCCA-3'), F16S-23SITS (5'-TGTACACACCGC CCGTCAC- $3^{\prime}$ ) and R16S-23SITS (5'-CTCTGTGTGC CTAGGTATCC $\left.-3^{\prime}\right)^{26}$, and FcpcB-cpcIGS ( $5^{\prime}$ - TTGCC T(G/T)CGCGACATGGAAAT - $3^{\prime}$ ) and RcpcB-cpcAIGS (5'-AGAGCTTCAAC(G/A)TACCAGCT- $3^{\prime}$ ) ${ }^{11}$, respectively. PCR reaction was performed as previously described by Phunpruch et $\mathrm{al}^{27}$. Each $50 \mu \mathrm{l}$ PCR reaction contained $20 \mathrm{mM}$ Tris- $\mathrm{HCl}$ (pH 8.5), $50 \mathrm{mM}$ $\mathrm{KCl}, 1.5 \mathrm{mM} \mathrm{MgCl}_{2}, 200 \mu \mathrm{M}$ dNTPs, $0.25 \mu \mathrm{M}$ of each primer, $0.05 \mathrm{U}$ of Taq DNA polymerase (Promega, USA) and $0.1 \mu \mathrm{g}$ of Geitlerinema genomic DNA. The PCR program consisted of an initial denaturation step at $94^{\circ} \mathrm{C}$ for $5 \mathrm{~min}$, followed by 35 cycles of denaturation at $94^{\circ} \mathrm{C}$ for $30 \mathrm{~s}$, annealing at $55-60^{\circ} \mathrm{C}$ for $1 \mathrm{~min}$, and extension at $72^{\circ} \mathrm{C}$ for $5 \mathrm{~min}$ with a final extension at $72{ }^{\circ} \mathrm{C}$ for $10 \mathrm{~min}$. PCR products were purified using the Gel/PCR DNA fragments extraction kit (Geneaid, Taiwan) and sequenced in both directions with the Big-Dye terminator cycle sequencing ready reaction kit (Perkin Elmer, USA) using an ABI PRISM 3700 DNA analyser at First BASE Laboratories (Malaysia).

\section{RAPD analysis}

Twenty universal random 10-mer primers were screened for Random Amplification of Polymorphic DNA (RAPD) analysis of Geitlerinema strains. Only five primers, OPA-03 (5'-AGTCAGCCAC-3'), OPA05 (5'-AGGGGTCTTG-3'), OPA-07 (5'-GAAACGG GTG-3'), OPA-10 (5'-GTGATCGCAG-3'), and OPA19 (5'-CAAACGTCGG-3'), displayed polymorphism and were thus chosen for RAPD analysis. Amplification was conducted in $25 \mu \mathrm{l}$ PCR reactions containing $20 \mathrm{mM}$ Tris- $\mathrm{HCl}$ (pH 8.5), $50 \mathrm{mM} \mathrm{KCl}, 1.5 \mathrm{mM}$ $\mathrm{MgCl}_{2}, 200 \mu \mathrm{M}$ dNTPs, $0.25 \mu \mathrm{M}$ of each primer, $0.05 \mathrm{U}$ of Taq DNA polymerase (Promega, USA) and $0.05 \mu \mathrm{g}$ of template DNA. The PCR program consisted of an initial denaturation step at $94^{\circ} \mathrm{C}$ for $5 \mathrm{~min}$, followed by 40 cycles of denaturation at $94^{\circ} \mathrm{C}$ for $1 \mathrm{~min}$, annealing at $40^{\circ} \mathrm{C}$ for $1 \mathrm{~min}$, and extension at $72^{\circ} \mathrm{C}$ for 2 min with a final extension at $72^{\circ} \mathrm{C}$ for $7 \mathrm{~min}$. PCR products were analysed by $2 \%(\mathrm{w} / \mathrm{v})$ agarose gel electrophoresis staining with $0.5 \mu \mathrm{g} / \mathrm{ml}$ ethidium bromide (Bio Basic, USA). A voltage gradient of $8 \mathrm{~V} / \mathrm{cm}$ was applied into the gel. After electrophoresis, the gel was illuminated under a UV light.

\section{Phylogenetic analysis}

The 16S rDNA, 16S-23S ITS, and сpcB-cpcA IGS nucleotide sequences were compared with those of Geitlerinema or other cyanobacteria available in the GenBank nucleotide database by multiple sequence alignment analysis using the CLUSTALW ${ }^{28}$. Maximum likelihood (ML) trees were constructed with molecular evolutionary genetics analysis (MEGA) software version $6.06^{29}$. The nucleotide substitution with complete-deletion gap treatment using the evolutionary model of Tamura and $\mathrm{Nei}^{30}$ was used for analysis. Bootstrap values were obtained from 1000 replicates for each database. For ML tree construction of 16S rDNA, 16S rDNA sequence of Gloeobacter violaceus was used as cyanobacterial outgroup and that of $E$. coli as distant outgroup. The ML phylogenetic tree of 16S-23S ITS sequences of 20 Geitlerinema isolates and other Geitlerinema strains was constructed using MEGA with 16S-23S ITS of another cyanobacterium, Phormidium autumnale CCALA 850, as an outgroup sequence. Each RAPD pattern was analysed from RAPD fingerprints generated on an agarose gel. To construct binomial matrix, the presence of a band at each position on a gel was scored as " 1 " while the absence was scored as " 0 ". The similarity index was used to calculate the genetic distance values and to construct the dendrogram. The data matrix based on Jaccard's similarity coefficient and phylogenetic dendrogram was conducted with the unweighted pair-group method with arithmetic averages (UPGMA) analysis using NTSYSpc 2.01e program. 
Table 1 Morphological characteristics comprising cellular width, cellular length, and number of cyanophycin granules per cell of marine Geitlerinema strains isolated from Thailand!

\begin{tabular}{|c|c|c|c|c|c|c|c|c|c|c|c|c|c|}
\hline \multirow[t]{2}{*}{ No. } & \multirow[t]{2}{*}{ Isolates } & \multicolumn{3}{|c|}{ Width $(\mu \mathrm{m})$} & \multicolumn{3}{|c|}{ Length $(\mu \mathrm{m})$} & \multirow[t]{2}{*}{$\mathrm{L}: \mathrm{W}$} & \multicolumn{5}{|c|}{ Granules } \\
\hline & & Min-Max & Mean & SD & Min-Max & Mean & SD & & 1 & 2 & 3 & 4 & $n \mathrm{G}$ \\
\hline 1 & CHL-SH1 & $2.22-2.50$ & 2.28 & 0.11 & $4.09-6.80$ & 5.09 & 1.01 & 2.23 & 15 & 7 & 2 & 0 & 24 \\
\hline 2 & JM-SH2 & $2.22-2.78$ & 2.33 & 0.17 & $3.18-5.45$ & 4.27 & 0.68 & 1.83 & 12 & 14 & 2 & 0 & 28 \\
\hline 3 & KM-SH3 & $1.67-2.22$ & 1.82 & 0.19 & $1.82-3.18$ & 2.59 & 0.46 & 1.42 & 18 & 9 & 1 & 0 & 28 \\
\hline 4 & LK-SH2 & $2.22-2.78$ & 2.38 & 0.21 & $3.18-6.80$ & 4.73 & 1.00 & 1.99 & 15 & 12 & 1 & 0 & 28 \\
\hline 5 & MTN-SH5 & $1.67-2.22$ & 2.07 & 0.25 & $3.18-9.55$ & 6.36 & 1.86 & 3.07 & 15 & 7 & 0 & 0 & 22 \\
\hline 6 & MTN-SH9 & $1.67-2.22$ & 1.82 & 0.17 & $3.18-5.90$ & 4.18 & 0.78 & 2.30 & 20 & 7 & 3 & 0 & 30 \\
\hline 7 & N-ST1 & $1.67-2.22$ & 1.83 & 0.16 & $2.73-4.55$ & 3.64 & 0.64 & 1.99 & 14 & 8 & 0 & 0 & 22 \\
\hline 8 & N-ST2 & $1.67-1.94$ & 1.82 & 0.14 & $3.18-7.73$ & 5.86 & 1.41 & 3.22 & 10 & 15 & 7 & 1 & 33 \\
\hline 9 & NM-SA4 & $1.67-2.22$ & 1.89 & 0.28 & $3.64-5.45$ & 4.45 & 0.60 & 2.35 & 16 & 8 & 1 & 0 & 25 \\
\hline 10 & NM-SH1 & $2.22-2.78$ & 2.57 & 0.25 & $3.24-5.16$ & 4.20 & 0.58 & 1.63 & 17 & 5 & 0 & 0 & 22 \\
\hline 11 & PI-S1.1 & $1.67-2.22$ & 1.67 & 0.20 & $3.18-5.00$ & 4.23 & 0.54 & 2.53 & 15 & 13 & 2 & 0 & 30 \\
\hline 12 & PM-SH13 & $1.94-2.22$ & 2.10 & 0.14 & $3.64-5.45$ & 4.86 & 0.58 & 2.31 & 18 & 6 & 1 & 0 & 25 \\
\hline 13 & RMK-SH10 & $1.67-1.94$ & 1.82 & 0.14 & $2.73-4.55$ & 3.64 & 0.54 & 2.00 & 12 & 14 & 2 & 0 & 30 \\
\hline 14 & S-SH3 & $1.67-2.22$ & 2.13 & 0.16 & $2.73-5.45$ & 4.18 & 0.86 & 1.96 & 15 & 11 & 2 & 0 & 28 \\
\hline 15 & SK-ST1.1 & $1.94-2.22$ & 2.11 & 0.14 & $2.73-6.80$ & 5.00 & 1.27 & 2.37 & 21 & 6 & 1 & 0 & 28 \\
\hline 16 & SK-ST1.2 & $1.67-2.22$ & 1.94 & 0.13 & $3.64-6.80$ & 5.45 & 0.86 & 2.81 & 11 & 7 & 4 & 1 & 23 \\
\hline 17 & SR-SH4 & $1.67-2.22$ & 1.92 & 0.15 & $3.18-7.27$ & 5.50 & 1.05 & 2.86 & 19 & 5 & 3 & 0 & 27 \\
\hline 18 & SSH-SH12 & $2.22-2.78$ & 2.64 & 0.23 & $3.18-5.45$ & 4.50 & 0.66 & 1.70 & 21 & 4 & 0 & 0 & 25 \\
\hline 19 & ST-ST1.5.1 & $1.67-2.22$ & 1.88 & 0.24 & $3.18-5.00$ & 4.05 & 0.66 & 2.15 & 12 & 8 & 0 & 2 & 22 \\
\hline 20 & TL-SH2 & $1.67-2.22$ & 1.94 & 0.22 & $3.64-5.45$ & 4.59 & 0.59 & 2.37 & 18 & 5 & 3 & 0 & 26 \\
\hline
\end{tabular}

${ }^{\dagger}$ Mean and SD of cell width and length were calculated from 20 measurements. L:W is the ratio of average length and width; $n \mathrm{G}$ is the total number of granules.

\section{Secondary structure of transfer RNA based on the 16S-23S ITS region}

The secondary structure of each tRNA was predicted by using MFold 3.2 (www.bioinfo.rpi.edu/ applications $/ \mathrm{mfold} /)^{31}$ with the folding temperature at $37^{\circ} \mathrm{C}$.

\section{RESULTS}

\section{Morphological characteristics}

By isolation of marine cyanobacteria from samples of seawater, stones, sand, and shells, randomly collected from the Gulf of Thailand and the Andaman Sea, a total of 175 cyanobacterial strains belonging to seven different genera were isolated from 40 coastal locations. Among them, 147 isolates were identified by $16 \mathrm{~S}$ rDNA sequencing analysis as Geitlerinema. Morphological and genetic characterization was performed on the representative 20 marine Geitlerinema isolates, which included 16 isolates from the Andaman Sea and four isolates from the Gulf of Thailand (Fig. 1). Using a light microscope, the morphology of these isolates was observed to be a flexuous or straight filament composed of a single trichome. The trichome was not constricted at the cross walls and was attenuated towards their ends. Each individual trichome contained one or more granules of cyanophycin (Table 1), one of which was close to the cross wall. In addition, the apical cells were rounded-cones without calyptrae at the outer cell wall (Fig. 2). Although all 20 Geitlerinema isolates showed the similar cellular shape, they appeared in a wide variety of trichome sizes. In this study, the average cellular length and width of the Geitlerinema strains were 2.59$6.36 \mu \mathrm{m}$ and 1.67-2.64 $\mu \mathrm{m}$, respectively, and the cellular length/width ratio ranged from 1.42-3.22 (Table 1). A single granule per cell was mostly observed in Geitlerinema (30-84\%) whereas two or three granules per cell were less observed (16-50\% and $0-21 \%$, respectively). Four granules per cell were observed in only three strains (isolates N-ST2, SK-ST1.2 and ST-ST1.51) (Table 1).

\section{Phylogenetic tree analysis of 16S rDNA}

Fragments of 16S rDNA were amplified and sequenced for all twenty marine Geitlerinema isolates. The resulting $960 \mathrm{bp}$ nucleotide sequences were deposited in GenBank under accession numbers KX955234-KX955253 and compared with those of other Geitlerinema and cyanobacterial strains. Maximum likelihood (ML) phylogenetic analysis of the 


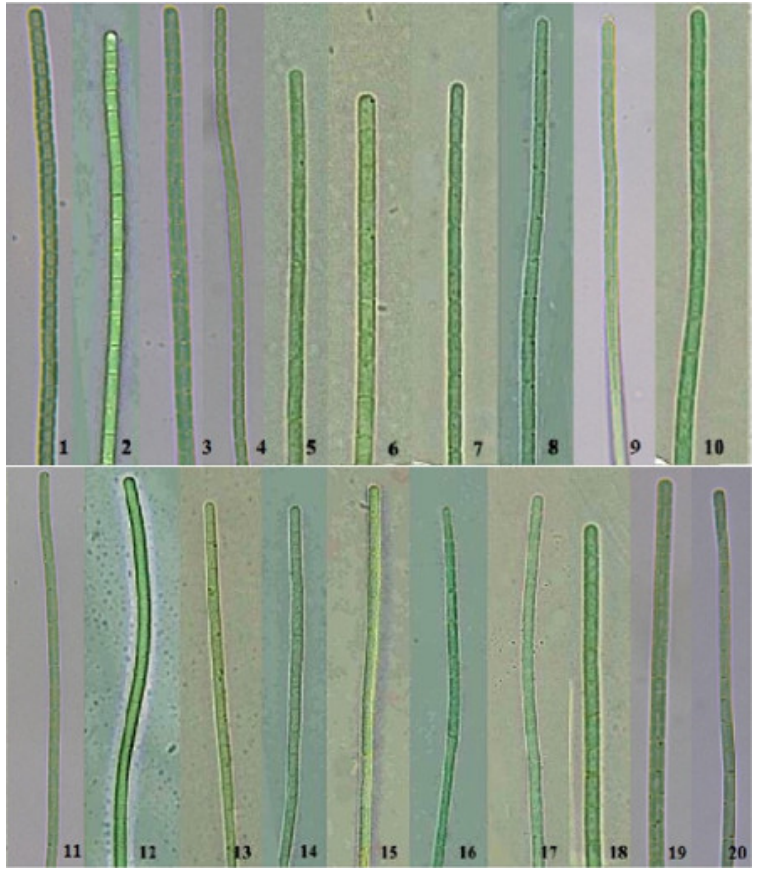

Fig. 2 Morphologies of marine Geitlerinema strains isolate from Thailand; Geitlerinema sp. CHL-SH1 (1), JM-SH2 (2), KM-SH3 (3), LK-SH2 (4), MTN-SH5 (5), MTN-SH9 (6), N-ST1 (7), N-ST2 (8), NM-SA4 (9), NM-SH1 (10), PIS1.1 (11), PM-SH13 (12), RMK-SH10 (13), S-SH3 (14), SK-ST1.1 (15), SK-ST1.2 (16), SR-SH4 (17), SSH-SH12 (18), ST-ST1.5.1 (19), and TL-SH2 (20).

16S rDNA sequences was performed. The resulting phylogenetic tree shows three clades of this genus (Fig. 3). All Geitlerinema isolates from Thailand (both from the Gulf of Thailand and the Andaman Sea) were clustered in the "Marine Geitlerinema" (Fig. 3). Interestingly, Geitlerinema sp. A28DM, Geitlerinema sp. Flo1 and Geitlerinema sp. PCC7105 were also clustered into this clade. The second Geitlerinema clade comprised many strains of freshwater Geitlerinema splendidum (strain P014, P017, SERB48 and PSE0519C) (Fig. 3). The third clade was composed of many strains of freshwater Geitlerinema species and Leptolyngbya species which were recently designated as Anagnostidinema pseudacutissimum and A. amphibium ${ }^{32}$ (Fig. 3).

\section{Phylogenetic analysis of the 16S-23S ITS}

The 570-580 bp DNA fragments of 16S-23S ITS of twenty marine Geitlerinema isolates were sequenced and the nucleotide sequences were deposited in the GenBank database under accession numbers KT186109-KT186128. The sequences showed $86.5-100 \%$ nucleotide similarity to each other. Compared with other Geitlerinema strains deposited in GenBank, the sequences showed 41.999\% nucleotide similarity, with the highest similarity (86.6-99\%) to Geitlerinema sp. Flo1 (accession No. FJ042948.1) and Geitlerinema sp. PCC7105 (accession No. FJ042946.1). The ML phylogenetic tree of the 16S-23S ITS sequences shows that Geitlerinema could be divided into four clades with a bootstrap value of $>90 \%$ (Fig. 4). All marine Geitlerinema strains isolated from Thailand, Geitlerinema sp. Flo1, and Geitlerinema sp. PCC7105 were clustered into clade I; G. pseudacutissimum and G. carotinosum were clustered into clade II; $G$. unigranulatum, G. lemmermannii, and G. amphibium were clustered into clade III; and G. acuminatum and G. splendidum were clustered into clade IV (Fig. 4).

The 16S-23S ITS nucleotide sequences among Geitlerinema sp. collected from Thailand (clade I) were subdivided into 4 groups. Sequences of each representative subgroup (Geitlerinema sp. RMKSH10, LK-SH2, ST-ST1.5.1, and TL-SH2) were compared with that of Geitlerinema sp. PCC7105. The results showed that the 16S-23S ITS of Geitlerinema sp. RMK-SH10 is 9-10 nucleotides longer than that of other strains. All the sequences contain the conserved domains (D1, D1', D2, D3, D4, D5, and the antiterminator boxA), which are the regions involved in the formation of stem-loop structure (V2, V3 and the antiterminator boxB), and two tRNA sequences (tRNA ${ }^{\text {Ile }}$ and tRNA ${ }^{\text {Ala }}$ ) (Fig. 5). The tRNA $^{\text {Ile }}$ gene is located downstream of the 16S rDNA whereas the $\mathrm{tRNA}^{\mathrm{Ala}}$ is located upstream of the 23S rDNA (Fig. 5). Almost all tRNA ${ }^{\text {Ala }}$ secondary structures of the Geitlerinema sp. assessed in this study have three loops (the small bubble above, the side loop, and the terminal loop), except for the structure of Geitlerinema sp. RMK-SH10, which contains only two loops due to the presence of 9-10 additional nucleotides.

\section{Phylogenetic analysis of the $c p c B-c p c A$ IGS}

DNA fragments of 90-91 bp region of the $c p c B-c p c A$ IGS of twenty marine Geitlerinema isolated in Thailand were sequenced and deposited in the GenBank database under accession numbers KT228281KT228300. A multiple sequence alignment revealed that the obtained nucleotide sequences are highly similar (95.6-100\%) to each other and show 42.7$99 \%$ similarity to other Geitlerinema strains reported in GenBank. The results showed that Geitlerinema could be divided into three clades with a bootstrap 


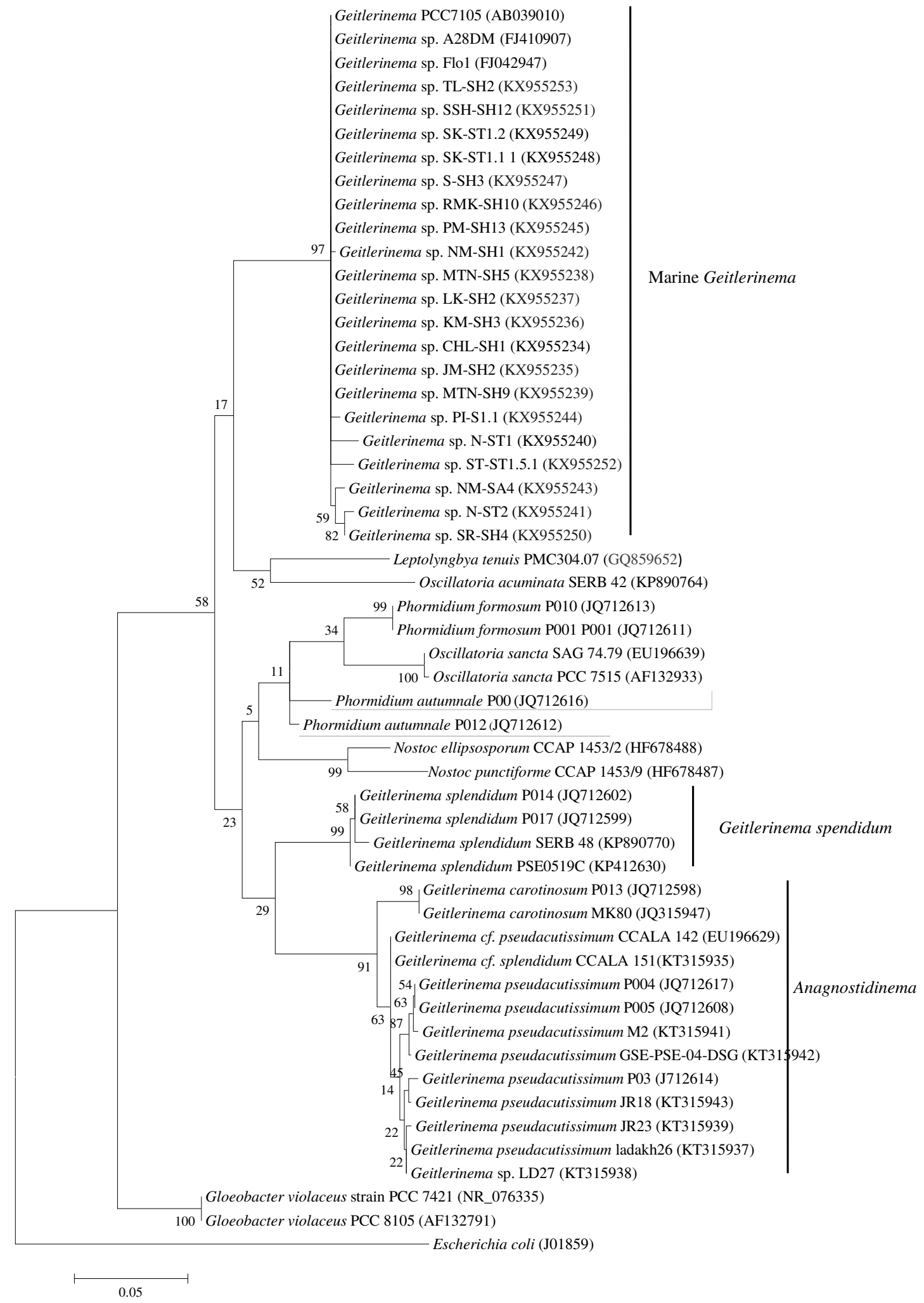

Fig. 3 The maximum likelihood (ML) phylogenetic tree based on the $16 \mathrm{~S}$ rDNA sequences of twenty marine Geitlerinema isolates and other cyanobacterial strains with 1000 bootstrap replicates. 


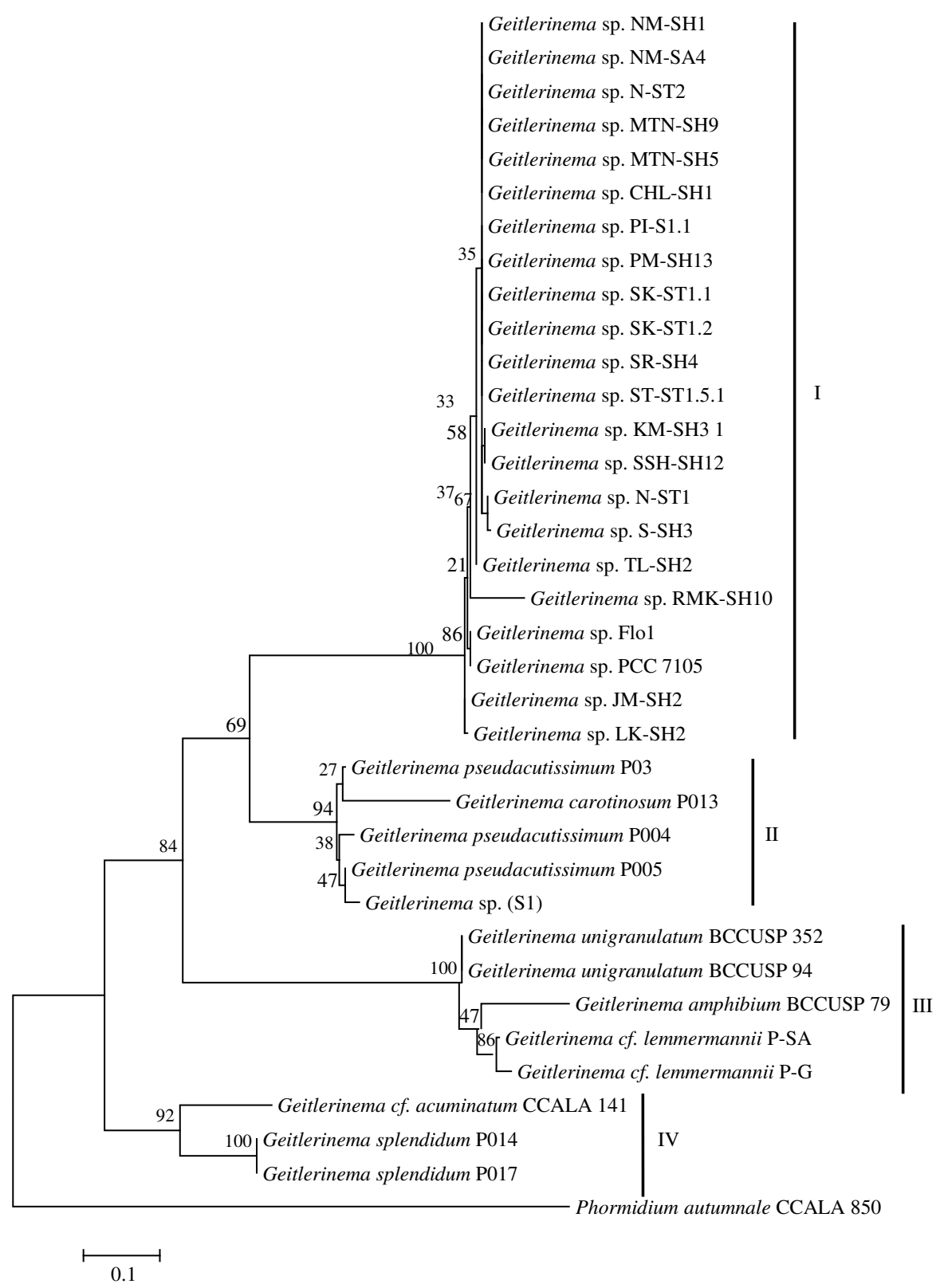

Fig. 4 The maximum likelihood (ML) phylogenetic tree based on the 16S-23S rRNA ITS sequences of twenty marine Geitlerinema isolates and other Geitlerinema strains with 1000 bootstrap replicates.

value of $>90 \%$ (Fig. 6). All Geitlerinema isolates from Thailand, Geitlerinema sp. Flo1 (accession No. FJ042941.1), and Geitlerinema sp. PCC7105 (accession No. FJ042942.1) were clustered into Clade I. In addition, Geitlerinema sp. LK-SH2 and Geitlerinema sp. JM-SH2 were genetically similar (Fig. 6). Clades II and III contained many strains of $G$. unigranulatum and G. amphibium (Fig. 6). The $c p c B-c p c A$ IGS region of Geitlerinema species in clade I comprised 86-91 nucleotides in length, and was distinct from those of clade II and clade III that contained 83 and 291-294 nucleotides, respectively.

\section{RAPD analysis}

RAPD pattern analysis was performed for twenty marine Geitlerinema isolates using the selected five primers, constructing 85 different PCR product bands that yielded $100 \%$ polymorphism. Each individual primer generated 14-17 identical PCR product bands. The size of the PCR products ranged from 


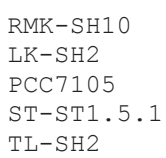

D1

CCTTTT AGGGAGACC GTTCCCCGATCGAGTGAAGGACGTTCGTGAGCCCACCCGATTGAG CCTTTTAGGGAGACCGTTCCCCAATCGAGTGAAGGATGTAAGTAAGCCCACCCGATTGAG CCTTTTAGGGAGACCGTTCCCCAATTGAGTGAAGGATATAAATAAGCCCACTCAATTGAG CCTTTTAGGGAGACCGTTCCCCGATCGAGTGAAGGCCGTTCGTGAGCCCACTCGATTGAG CCTTTTAGGGAGACCGTTCCCCGATCGAGTGAAGGACGTTCGTGAGCCCACTCGATTGAG

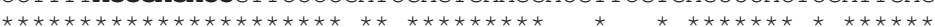

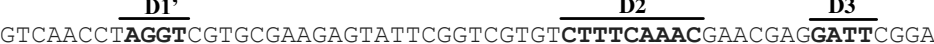
D3 GTCAACCTAGGTCGTACGAAGAGTATTCGGTCGTGTCTTTCAAACGAACGAGGATTCGGA GTCAACCTAGGTCGTGCGAAGAGTATTCGGTCGTGTCTTTCAAACGAACGAGGATTCGGA GTCAACCTAGGTCGTGCGAAGAGTATTCGGTCGTGTCTTTCAAACGAACGAGGATTCGGA GTCAACCTAGGTCGTGCGAAGAGTATTCGGTCGTGTCTTTCAAACGAACGAGGATTCGGA

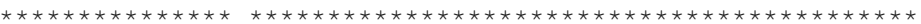

ATCTCAGTTTTCAGTTTTTTGAAAACTCGACGAGGCCGAAAAAACGG $\overline{\text { GGTTTTTACTTC }}$ ATCTCGGTTTTCAGTTTTTGAAA-ACTCG-ACGAGGCCGAAAAACGTGGGCTATTAGCTC ATCTCGGTTTTCAGTTTTTGAAA-ACTCG-ACGAGGCCGAAAAACGTGGGCTATTAGCTC ATCTCAGTTTTCAAACAACTGAAAACTCGACGAGGCCGAAAAAACGTGGGCTATTAGCTC ATCTCAGTTTTCAGTTTTTTGAAAACTCGACGAGGCCGA-AAAACGTGGGCTATTAGCTC

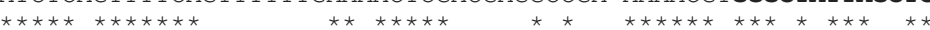
tRNA ${ }^{\text {Ile }}$

AGGGGGTTGAGGGGCACCCCTGGATAAGGGTGAGGTCCCTGGGTTCAGGTCCGGGAGGGC AGGTGGTTAGAGCGCACCCCTGAT-AAGGGTGAGGTCCCTG-GTTCAAGTCCAGGATGGC AGGTGGTTAGAGCGCACCCCTGAT-AAGGGTGAGGTCCCTG-GTTCAAGTCCAGGATGGC AGGTGGTTAGAGCGCACCCCTGAT-AAGGGTGAGGTCCCTG-GTTCAAGTCCAGGATGGC AGGTGGTTAGAGCGCACCCCTGAT-AAGGGTGAGGTCCCTG-GTTCAAGTCCAGGATGGC

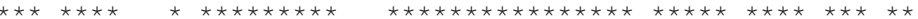

CCACTGGGTTCACCGAACAGCGAGCAGTAAAACAGTGGAAACAGTGAGAACTGGATGGGC CCACCTAATTCAGCGAGCAGTGAGCAGCAAACAGCGAGCAGTGAAA-------ACTGATG CCACCTGATTCAGCGAGCAGTGAGCAGCAAACAGCGAGCAGTGAAA-------ACTGATG CCACCTGGTTCAGCGAACAGCGAGCAGTAAACAGTGAACAGTGAAA-------ACTGATG CCACCTGATTCAGTGAACAGCGAGCAGTAAACAGTGAACAGTGAGA-------ACTGATG

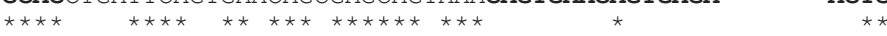

TGTTGTCTGGGTGACTGTTTAACTGAAAGAGTGGGGGTATAGCTCAGTTGGTAGAGCGCC ACTGGTGACTGGTGACTGTTAACTGAAATCGTGGGGGTATAGCTCAGTTGGTAGAGCGCC ACTGGTGACTGGTGACTGTTAACTGAAATCGTGGGGGTATAGCTCAGTTGGTAGAGCGCC GCTGTTGTCTGGTGACTGTTAACTGAAAGAGTGGGGGTATAGCTCAGTTGGTAGAGCGCC GCTGTTGTCTGGTGACTGTTAACTGAAAGAGTGGGGGTATAGCTCAGTTGGTAGAGCGCC

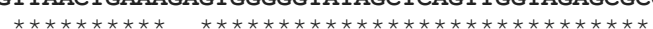
tRNA $^{\text {Ala }}$

TGCTTTGCAAGCAGGATGTCAGCGGTTCGAGTCCGCTTACCTCCA CGCTCGTCTCGTCAC TGCTTTGCAAGCAGGATGTCAGCGGTTCGAGTCCGCTTACCTCCACGCTCGTCTCGTCGC TGCTTTGCAAGCAGGATGTCAGCGGTTCGAGTCCGCTTACCTCCACGCTCGTCTCGTCGC TGCTTTGCAAGCAGGATGTCAGCGGTTCGAGTCCGCTTACCTCCACGCTCGTCTCGTCGC TGCTTTGCAAGCAGGATGTCAGCGGTTCGAGTCCGCTTACCTCCACGCTCGTCTCGTCGC

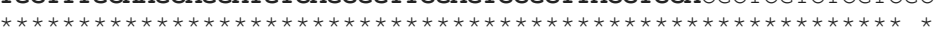
Box $\mathrm{B}<$

CACTCGACCCTCGAAACCCAAACGATTCTAATCGGAAAGGGAGTTCAGCACCCGAGAGAC CACTCGAACCTCGAATCCCAAACGATTCTAATCGGAAAGGGAGTTCAGCACCCGAGAGAG CACTCGAACCTCGAATCCCAAACGATTCTAATCGGAAAGGGAGTTCAGCACCCGAGAGAG CACTCGACCCTCGAAACCCAAACGATTCAAATCGGAAAGGGAATTCAGCACCCGAGAGAG CACTCGACCCTCGAAACCCAAACGATTCTAATCGGAAAGGGAATTCAGCACCCGAGAGAG

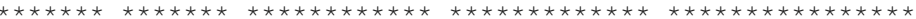

$$
\text { Box A D4 }
$$

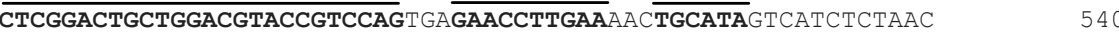
СTCGGACTGCTGGACGTACCGTCCAGTAAGAACCTTGAAAACTGCATAGTCATCTCTAAA CTCGGACTGCTGGACGTACCGTCCAGTAAGAACCTTGAAAACTGCATAGTCATCTCTAAA 529 СTCGGACTGCTGGACGTCCCGTCCAGTGAGAACCTTGAAAACTGCATAGTCATCTCTAAA CTCGGACTGCTGGACGTCCCGTCCAGTGAGAACCTTGAAAACTGCATAGTCATCTCTAAC 530

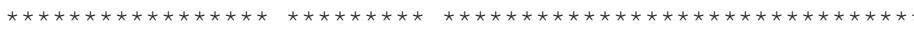

\section{D5}

AAAGT-AAAGCTAGGGAAAGCGAGACCTCGCGCATTGAGG $\quad 580$

CAAAGTAAAGCTAGGGAAGCCGAGACCTCGCGAATAGAGG $\quad 570$

CAAAGTAAAGCTAGGGAAAGCCGAGACCTCGCGAATAGAGG $\quad 570$

AAAGT-AAAGCTAGGGAAAGCGAGACCTCGCGCATTGAGG 571

AAAGT-AAAGCTAGGGAAAGCGAGACCTCGCGCATTGAGG 570
60

60

60

60

Fig. 5 Alignment of 16S-23S rRNA ITS sequences of Geitlerinema sp. TL-SH2, LK-SH2, ST-ST1.5.1 and RMK-SH10 compared to that of Geitlerinema sp. PCC7105. All sequences contain tRNA ${ }^{\text {Ile }}$, tRNA $^{\text {Ala }}$, the consensus domain sequences (D1-D5), the antiterminator (boxB and boxA) and the major variable stems V2 and V3. 


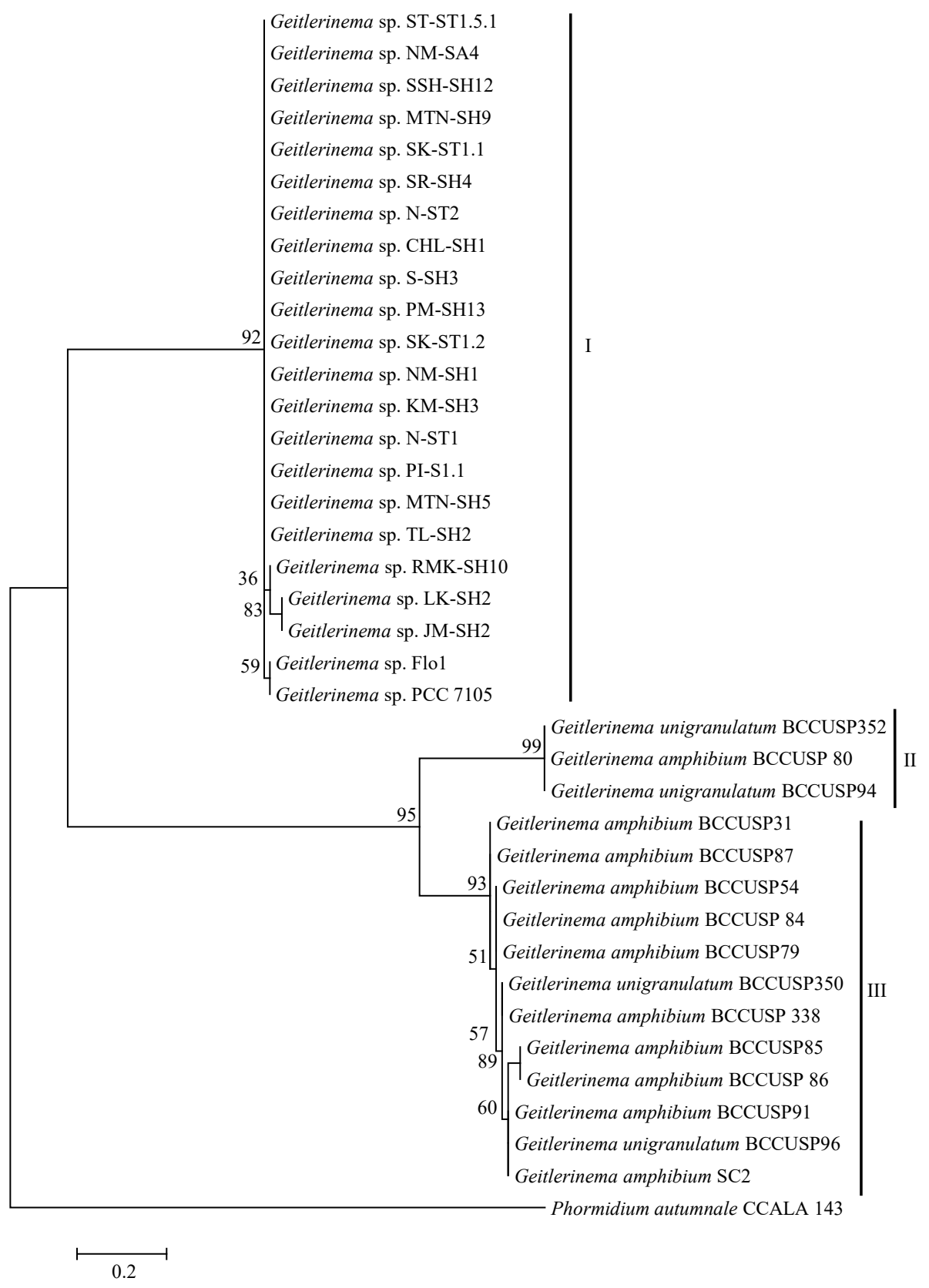

Fig. 6 The maximum likelihood (ML) phylogenetic tree based on the $c p c B-c p c A$ IGS sequences in twenty marine Geitlerinema isolates and other Geitlerinema strains with 1000 bootstrap replicates.

600-4000 bp. The RAPD patterns and similarity matrix of Geitlerinema isolates using five selected primers. The RAPD tree exhibited eight clades with an average similarity coefficient of 0.71 (Fig. 7). Clade I contained Geitlerinema sp. KM-SH3 and clade II contained Geitlerinema sp. PI-S1.1. Clade III contained 12 Geitlerinema strains, including three Geitlerinema isolates (SK-ST1.2, ST-ST1.5.1 and SKST1.1) from the Gulf of Thailand and nine iso- lates from the Andaman Sea. The similarity within clade III ranged from $71.1-90 \%$. The remaining six isolates from the Andaman Sea were classified into five clades: Geitlerinema sp. TL-SH2 in clade IV, Geitlerinema sp. N-ST1 in clade V, Geitlerinema sp. PM-SH13 in clade VI, Geitlerinema sp. CHLSH1 in clade VII, and Geitlerinema sp. LK-SH2 and Geitlerinema sp. JM-SH2 in clade VIII (Fig. 7). The similarity within clade VIII was $74 \%$. 


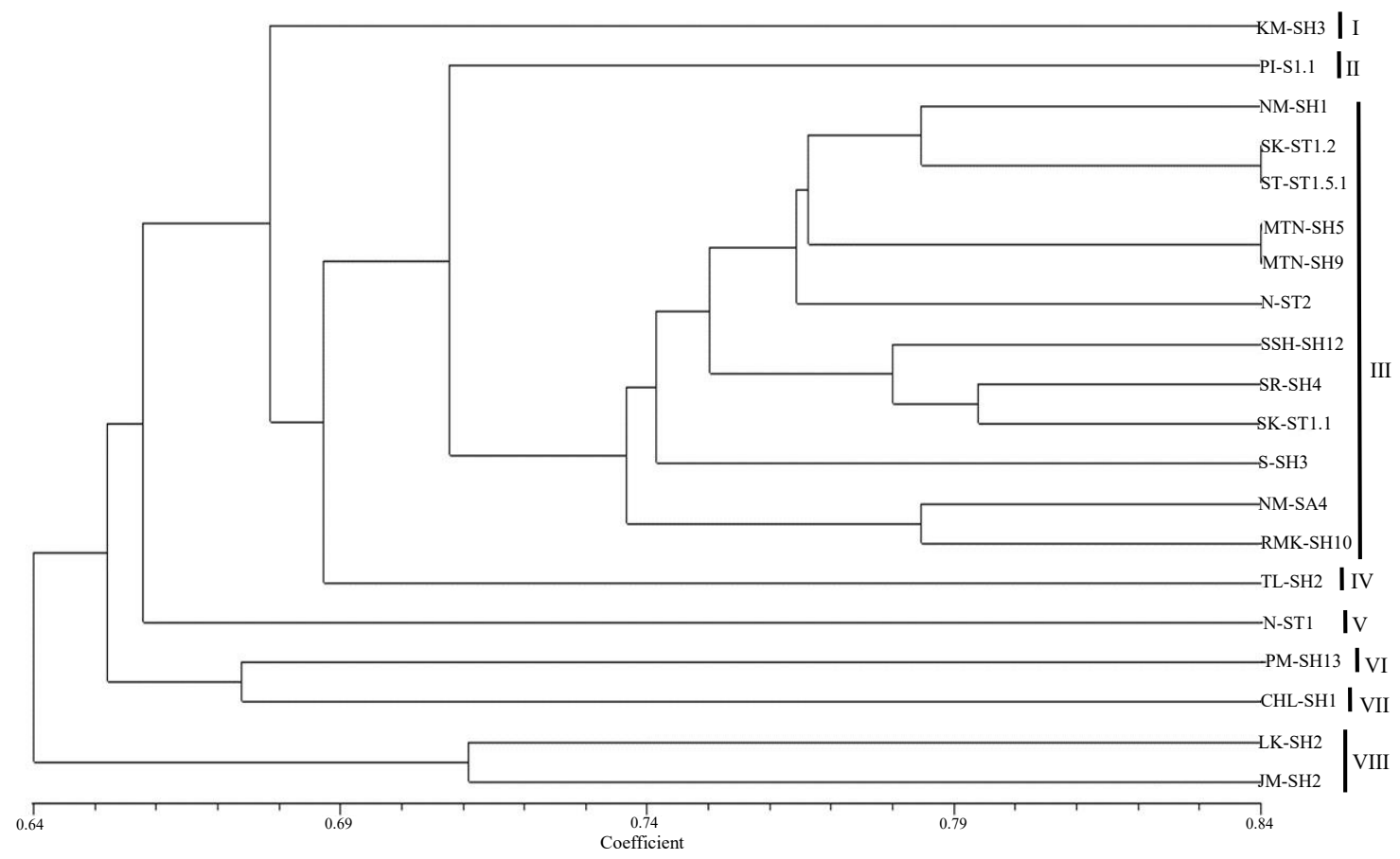

Fig. 7 Dendrogram showing the relationship of marine Geitlerinema isolates based on UPGMA cluster analysis of the RAPD profiles derived using five primers and Jaccard's similarity coefficient.

\section{DISCUSSION}

The marine cyanobacterial isolates from the Gulf of Thailand and the Andaman Sea mostly belonged to genus Geitlerinema. Although samples were randomly collected, it was quite easy for isolation benthic cyanobacteria attached to shells and stones due to the trichome structure and the obvious bluegreen colour appearance. In this study, 20 Geitlerinema isolates, representatives from the different locations, were subjected to morphological and phylogenetic analyses. All isolates studied correspond to one single morphological type and all of them are similar to G. pseudacutissimum and G. carotinosum whose morphology has been previously reported by Hašler et $\mathrm{al}^{10}$. However, our isolates are different from the type species of Geitlerinema, G. splendidum P014 and G. splendidum P017 which are bent or screw-like at the ends with capitate or rounded apical cells ${ }^{10}$. Furthermore, G. amphibium and G. unigranulatum formed a flexuous to straight trichome with no constriction at the cross walls but with rounded-conical apical cells. Their hooked apical cells were observed in cultures ${ }^{17}$. In this study, the observed cellular length was similar to that of G. amphibium and G. unigranulatum, which are 2.2$7 \mu \mathrm{m}$ long, but the observed cellular width was quite wider than those organisms, which are 1.02$1.91 \mu \mathrm{m}$ wide, as well as the number of granules ${ }^{17}$. Since all Geitlerinema strains investigated show the similar morphological data, using genetic information might help to assess the variation among Geitlerinema strains in this study.

The 16S rDNA phylogenetic tree shows that all Geitlerinema isolates from Thailand were clustered in the same clade designated as "marine Geitlerinema" (Fig. 3). These results indicate that marine Geitlerinema isolates from Thailand are genetically similar to each other and closely related to many marine Geitlerinema strains, Geitlerinema sp. A28DM isolated from sandy shores parallel to the coast indented by the estuarine mouth of river Tapi, Gujarat, India ${ }^{33}$, Geitlerinema sp. Flo1 (Oscillatoria limnetica Flo1), present in the culture collection of the Department of Marine Microbiology at the University of Bremen ${ }^{34}$ and Geitlerinema sp. PCC7105, recognized as the reference strain for the marine species of this genus according to Bergey's Manual $^{1}$. This clade was phylogenetically distant from other freshwater Geitlerinema clades which are consistent with previous reports ${ }^{19,32}$. Recently, Strunecký and coworkers revised the genus of Geitlerinema that Geitlerinema splendidum was only one species according to the morphological similarity 
with its origin description but other Geitlerinema or Leptolyngbya species was proposed to transfer into Anagnostidinema gen. nov. ${ }^{32}$. Our result and the previous study clearly demonstrated that marine Geitlerinema is phylogenetically distant from other freshwater Geitlerinema and might be separated into other genera of cyanobacteria. The 16S rDNA sequences have been used as a target region for identification and phylogenetic analysis of several cyanobacteria; however, the data are insufficient to guarantee species identity and genetic diversity because of a lower evolutionary rate of variation ${ }^{35}$. With this reason, we investigated other variable nucleotide sequence regions such as 16S-23S ITS and $c p c B-c p c A$ IGS.

From the Maximum Likelihood phylogenetic tree of the 16S-23S ITS sequences, marine Geitlerinema isolates from Thailand are genetically similar to each other and are closely related to Geitlerinema sp. Flo1 and Geitlerinema sp. PCC7105 but are different from other freshwater Geitlerinema strains found in central Europe such as G. carotinosum, G. pseudacutissimum, and G. see acuminatum. It was suggested that 16S-23S ITS sequence analysis could be used to primarily classify Geitlerinema strains at the species level based on the highly variable nucleotide sequences; however, this was not possible due to the limited genetic variation among the strains assessed in this study.

The 16S-23S ITS nucleotide sequences among marine Geitlerinema sp. collected from Thailand (clade I) were subdivided into four groups. Sequences of each representative subgroup (Geitlerinema sp. RMK-SH10, LK-SH2, ST-ST1.5.1, and TLSH2) were compared with that of Geitlerinema sp. PCC7105. All the sequences contain the conserved domains (D1, D1', D2, D3, D4, D5, and the antiterminator boxA), which are the regions involved in the formation of stem-loop structure (V2, V3 and the antiterminator boxB), and two tRNA sequences (tRNA $^{\text {Ile }}$ and tRNA ${ }^{\text {Ala }}$ ) (Fig. 5).

Almost all tRNA ${ }^{\text {Ala }}$ secondary structures of the Geitlerinema sp. assessed in this study have three loops (the small bubble above, the side loop, and the terminal loop), except for the structure of Geitlerinema sp. RMK-SH10, which contains only two loops due to the presence of 9-10 additional nucleotides. Geitlerinema sp. RMK-SH10 may be genetically diverse from other strains in the subgenus. A comparative analysis of tRNA secondary structure might be a useful tool for studying genetic diversity among individual species of cyanobacteria.

From the Maximum Likelihood phylogenetic tree of the $c p c B-c p c A$ IGS sequences Geitlerinema could be divided into three clades. All twenty marine Geitlerinema isolates from Thailand, Geitlerinema sp. Flo1, and Geitlerinema sp. PCC7105 were classified into Clade I (Fig. 6). This result is similar to those based on 16S rDNA and 16S$23 \mathrm{~S}$ ITS sequences. It also confirmed the close genetic relationship among these marine Geitlerinema species. It was previously reported that the nucleotide sequences of cyanobacterial $c p c B-c p c A$ IGS ranged from 69-298 nucleotides ${ }^{36}$. Since the length of $c p c B$-cpcA IGS sequence is variable compared with that of the 16S-23S ITS sequence, the former might yield information enabling the differentiation at the strain level. However, this was not the case for the highly similar Geitlerinema isolates from Thailand assessed in this study.

In general, the DNA fingerprint obtained by RAPD is a molecular technique used for cluster analysis in order to study geographic patterns and to examine genetic diversity among cyanobacteria $^{16,37,38}$. In this work, eight clades of marine Geitlerinema could be separated using by this method, revealing the genetic relationship among Geitlerinema populations. Within clade III, 12 Geitlerinema strains could be divided into many subgroups depending on the similarity coefficient. Geitlerinema sp. ST-ST1.5.1 was most closely related to Geitlerinema sp. SK-ST1.2 whereas Geitlerinema sp. MTNSH5 was most closely related to Geitlerinema sp. MTN-SH9 (Fig. 7). Interestingly, Geitlerinema sp. LK-SH2 and JM-SH2 were not separated from other strains based on 16S-23S ITS sequence (Fig. 4) and $c p c B-c p c A$ IGS sequences (Fig. 6) but could be separated by RAPD. This was because the RAPD technique uses one short primer to randomly amplify DNA fragments to generate many PCR bands in a pattern. The polymorphic profiles generated by RAPD analysis suggested a considerable degree of intra-species heterogeneity ${ }^{39}$. However, previous reports demonstrated that although RAPD patterns of the cyanobacteria $L$. valderiana and $P$. retzii showed genetic diversity, they did not correspond to the distinct geographic area of isolation ${ }^{16,38}$. Thus a combination of both morphological and molecular data may facilitate the establishment of taxonomic diversity.

In summary, twenty marine Geitlerinema strains isolated from the Gulf of Thailand and the Andaman Sea in Thailand could not be phylogenetically distinguished from each other using morphology and molecular analyses of the 16S rDNA, 16S-23S ITS and the $c p c B-c p c A$ IGS sequences; however, DNA 
fingerprinting using RAPD analysis could separate all twenty marine Geitlerinema strains isolated from Thailand into eight clades without the correlation with geographic locations. In addition, by $16 \mathrm{~S}$ rDNA, 16S-23S ITS and the $c p c B-c p c A$ IGS sequence analysis, Geitlerinema isolated in this study was clustered in "marine Geitlerinema" group which is suggested to classify into other or new genera of cyanobacteria.

Acknowledgements: This work was supported by a research grant from the Faculty of Science, King Mongkut's Institute of Technology Ladkrabang (2558A11802077). A. Incharoensakdi thanks the Thailand Research Fund for financial support (IRG5780008).

\section{REFERENCES}

1. Castenholz RW, Wilmotte A, Herdman M, Rippka R, Waterbury JB, Iteman I, Hoffmann L (2001) Phylum BX. Cyanobacteria. In: Boone DR, Castenholz RW, Garrity GM (eds) Bergey's Manual of Systematic Bacteriology, Springer, New York, pp 473-599.

2. Rippka R, Deruelles J, Waterbury JB, Herdman M, Stanier RY (1979) Generic assignments, strain histories and properties of pure cultures of cyanobacteria. Microbiology 111, 1-61.

3. Anagnostidis K, Komárek J (1988) Modern approach to the classification system of cyanophytes. 3-Oscillatoriales. Algol Stud 50-53, 327-472.

4. Rippka R (1988) Recognition and identification of cyanobacteria. Meth Enzymol 167, 28-67.

5. Anagnostidis K (1989) Geitlerinema, a new genus of oscillatorialean cyanophytes. Plant Systemat Evol 164, 33-46.

6. Margheri MC, Piccardi R, Ventura S, Viti C, Giovannetti L (2003) Genotypic diversity of Oscillatoriacean strains belonging to the genera Geitlerinema and Spirulina determined by 16S rDNA restriction analysis. Curr Microbiol 46, 359-64.

7. Kirkwood AE, Henley WJ (2006) Algal community dynamics and halotolerance in a terrestrial, hypersaline environment. $J$ Phycol 42, 537-47.

8. Romo S, Miracle MR, Hernandez-Marine M (1993) Geitlerinema amphibium (Ag. ex Gom.) Anagnostidis (Cyanophyceae): morphology, ultrastructure and ecology. Algol Stud 69, 11-27.

9. Komárek J, Azevedo MTP (2000) Geitlerinema unigranulatum, a common tropical cyanoprokaryote from freshwater reservoirs in Brazil. Algol Stud 99, 39-52.

10. Hašler P, Dvořák P, Johansen JR, Kitner M, Ondřej V, Poulíčková A (2012) Morphological and molecular study of epipelic filamentous genera Phormiduim, Microcoleus and Geitlerinema (Oscillatoriales, Cyanophyta/Cyanobacteria). Fottea 12, 341-56.
11. Neilan BA, Jacobs D, Goodman AE (1995) Genetic diversity and phylogeny of toxic cyanobacteria determined by DNA polymorphisms within the phycocyanin locus. Appl Environ Microbiol 61, 3875-83.

12. Scheldeman P, Baurain D, Bouhy R, Scott M, Mühling M, Whitton BA, Belay A, Wilmotte A (1999) Arthrospira ('Spirulina') strains from four continents are resolved in only two clusters, based on amplified ribosomal DNA restriction analysis on the internally transcribed spacer. FEMS Microbiol Lett 172, 213-22.

13. Iteman I, Rippka R, Tandeau de Marsac N, Herdman $M$ (2000) Comparison of conserved structural and regulatory domains within divergent 16S rRNA-23S rRNA spacer sequences of cyanobacteria. Microbiology 146, 1275-86.

14. Ballot A, Dadheech P, Krientz L (2004) Phylogenetic relationship of Arthrospira, Phormidium, and Spirulina strains from Kenyan and Indian waterbodies. Algol Stud 113, 37-56.

15. Premanandh J, Priya B, Teneva I, Dzhambazov B, Prabaharan D, Uma L (2006) Molecular characterization of marine cyanobacteria from the Indian subcontinent deduced from sequence analysis of the phycocyanin operon ( $c p c B-I G S-c p c A)$ and $16 \mathrm{~S}-23 \mathrm{~S}$ ITS region. $J$ Microbiol 44, 607-16.

16. Premanandh J, Priya B, Prabaharan D, Uma L (2009) Genetic heterogeneity of the marine cyanobacterium Leptolyngbya valderiana (Pseudanabaenaceae) evidenced by RAPD molecular markers and 16S rDNA sequence data. J Plankton Res 31, 1141-50.

17. Bittencourt-Oliveira MC, Moura AN, Oliveira MC, Massola Jr NS (2009) Geitlerinema species (Oscillatoriales, Cyanobacteria) revealed by cellular morphology, ultrastructure and DNA sequencing. $J$ Phycol 45, 716-25.

18. Willame R, Boutte C, Grubisic S, Wilmotte A, Komárek J, Hoffmann L (2006) Morphological and molecular characterization of planktonic cyanobacteria from Belgium and Luxembourg. J Phycol 42, 1312-32.

19. Perkerson RB, Perkerson AE, Casamatta DA (2010) Phylogenetic examination of the cyanobacterial genera Geitlerinema and Limnothrix (Pseudanabaenaceae) using 16S rDNA gene sequence data. Algol Stud 134, 1-16.

20. Hašler P, Dvořák P, Poulíčková A (2014) A new genus of filamentous epipelic cyanobacteria, Johansenia. Preslia 86, 81-94.

21. Chunleuchanon S, Sooksawany A, Teaumroong N, Boonkerd N (2003) Diversity of nitrogen-fixing cyanobacteria under various ecosystems of Thailand: population dynamics as affected by environmental factors. World J Microbiol Biotechnol 19, 167-73.

22. Sompong U, Anuntalabhochai S, Cutler RW, Castenholz RW, Peerapornpisal Y (2008) Morphological and phylogenic diversity of cyanobacterial populations in six hot springs of Thailand. Sci Asia 34, 153-62. 
23. Chatchawin T, Peerapornpisal Y, Komárek J (2011) Diversity of cyanobacteria in man-made solar saltern, Petchaburi Province, Thailand - a pilot study. Fottea 11, 203-14.

24. Hoshaw RW, Rosowski JR (1973) Methods for microscopic algae. In: Stein JR (ed) Handbook of Phycological Methods, Culture Methods and Growth Measurements, Cambridge Univ Press, Cambridge, pp 54-66.

25. Golden SS, Brusslan J, Haselkorn R (1987) Genetic engineering of the cyanobacterial chromosome. Meth Enzymol 153, 215-31.

26. Boyer SL, Johensen JR, Flechtner VR, Howard GL (2002) Phylogeny and genetic variance in terrestrial Microcoleus (Cyanophyceae) species based on sequence analysis of the 16S rRNA gene and associated 16S-23S ITS region. J Phycol 38, 1222-35.

27. Phunpruch S, Baebprasert W, Thongpeng C, Incharoensakdi A (2006) Nucleotide sequencing and transcriptional analysis of uptake hydrogenase genes in the filamentous $\mathrm{N}_{2}$-fixing cyanobacterium Anabaena siamensis. J Appl Phycol 18, 713-22.

28. Thompson JD, Higgins DG, Gibson TJ (1994) CLUSTAL W: Improving the sensitivity of progressive multiple sequence alignment through sequence weighting, position-specific gap penalties and weight matrix choice. Nucleic Acids Res 22, 4673-80.

29. Tamura K, Stecher G, Peterson D, Filipski A, Kumar S (2013) MEGA6: molecular evolutionary genetics analysis (MEGA) software version 6.0. Mol Biol Evol 30, 2725-9.

30. Tamura K, Nei M (1993) Estimation of the number of nucleotide substitutions in the control region of mitochondrial DNA in humans and chimpanzees. $M o l$ Biol Evol 10, 512-26.

31. Zuker M (2003) Mfold web server for nucleic acid folding and hybridization prediction. Nucleic Acids Res 31, 3406-15.

32. Strunecký O, Bohunická M, JohanSen J R, Čapková K, RaaBová L, Dvořák P, Komárek J (2017) A revision of the genus Geitlerinema and a description of the genus Anagnostidinema gen. nov. (Oscillatoriophycidae, Cyanobacteria). Fottea 17, 114-26.

33. Parmar A, Singh NK, Madamwar D (2010) Allophycocyanin from a local isolate Geitlerinema sp. A28DM (cyanobacteria): a simple and efficient purification process. J Phycol 46, 285-9.

34. Schrübbers J, Heyduck-Söller B, Fischer U (2008) New classification systems and molecular methods necessitate the reclassification of the filamentous cyanobacterium Oscillatoria limnetica strain Flo1 as a species of the genus Geitlerinema. In: Komenda J, Knoppová J, Kubečkoá E (eds) Book of Abstracts, 7th European Workshop on the Molecular Biology of Cyanobacteria, České Budějovice, p 117.

35. Fox GE, Wisotzkey JD, Jurtshuk Jr P (1992) How close is close: $16 \mathrm{~S}$ rRNA sequence identity may not be sufficient to guarantee species identity. Int $J$ Syst Bacteriol 42, 166-70.

36. Bittencourt-Oliveira MC, Piccin-Santos V (2012) Genetic diversity of Brazilian cyanobacteria revealed by phylogenetic analysis. In: Caliskan M (ed) Genetic Diversity in Microorganisms, InTech, London, pp 275-90.

37. Moschetti G, Blaiotta G, Aponte M, Catzeddu P, Villani F, Deiana P, Coppola S (1998) Randomly amplified polymorphic DNA and amplified ribosomal DNA spacer polymorphism: powerful methods to differentiate Streptococcus thermophilus strains. J Appl Microbiol 85, 25-36.

38. Casamatta DA, Vis ML, Sheath RG (2003) Cryptic species in cyanobacterial systematic: a case study of Phormidium retzii (Oscillatoriales) using RAPD molecular markers and 16S rDNA sequence data. Aquat Bot 77, 295-309.

39. Saker ML, Neilan BA, Griffiths DJ (1999) Two morphological forms of Cylindrospermopsis raciborskii (Cyanobacteria) isolated from Solomon Dam, Palm Island, Queensland. J Phycol 35, 599-606. 